\title{
Uric Acid, Renal Vasoconstriction and Erythropoietin Relationship in IgA Nephropathy Revealed by Dopamine-Induced Glomerular Filtration Response
}

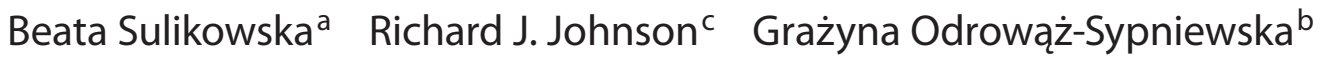 \\ Jacek Manitius ${ }^{a}$ \\ a Department of Nephrology, Hypertension and Internal Medicine, and ${ }^{b}$ Clinical Laboratory Medicine, \\ Nicolaus Copernicus University in Toruń, Collegium Medicum in Bydgoszcz, Bydgoszcz, Poland; \\ 'Division of Renal Disease and Hypertension, University of Colorado Denver, Aurora, Colo., USA
}

\section{Key Words}

Erythropoietin $\cdot \lg A$ nephropathy $\cdot$ Intrarenal vessel

function · Serum uric acid · Uric acid clearance

\begin{abstract}
Background: Elevated serum uric acid experimentally stimulates renal vasoconstriction and activation of the reninangiotensin system and consequently modulates erythropoietin (EPO) production. We used a dopamine-induced glomerular filtration response test (DIR) to assess whether elevated uric acid is associated with dopamine response and EPO levels in IgA patients. Methods: In 46 non-nephrotic IgA patients (age: $33.7 \pm 8.9$ years) and 15 controls (age: $33.5 \pm$ 6.9 years) with a glomerular filtration rate of $86.7 \pm 17.4$ and $118.1 \pm 17.2 \mathrm{ml} / \mathrm{min}$, respectively, renal vascular function was estimated based on DIR. DIR was measured using two 120-min creatinine clearances (before and after i.v. administration of $2 \mu \mathrm{g} / \mathrm{kg} / \mathrm{min}$ dopamine) and at the same points EPO was measured. Uric acid, cholesterol, triglycerides, urinary uric acid and $\mathrm{N}$-acetyl- $\beta$-D-glucosaminidase were measured. Results: Basal EPO was the same in IgA patients and controls (13.5 \pm 9.5 vs. $10.6 \pm 4.3 \mathrm{mU} / \mathrm{ml}$, respectively; NS); however, EPO correlated with uric acid clearance in IgA pa-
\end{abstract}

tients but not in controls ( $r=0.45, p<0.002$ vs. $r=0.25, p<$ 0.361 , respectively), and DIR tended to be lower in $\lg A$ nephropathy $(p<0.06$ ). A more pronounced slope between EPO and DIR as well as lower DIR/EPO was found in IgA patients. Conclusions: These results are consistent with greater renal vasoconstriction in IgA nephropathy that would stimulate EPO and reduce urate clearance.

Copyright $\odot 2011$ S. Karger AG, Basel

\section{Introduction}

Hyperuricemia is associated with increased risk of progression of renal disease in subjects with IgA nephropathy and is strongly associated with tubulointerstitial fibrosis and renal vascular changes $[1,2]$. Experimental studies suggest hyperuricemia may increase the risk of renal progression by inducing intrarenal vasoconstriction resulting in ischemia and tubulointerstitial fibrosis [3]. An inverse relationship between serum uric acid concentration and renal plasma flow has been observed in hypertensive patients [4]. Potential mechanisms for uric acid-mediated renal vasoconstriction include inhibitory effects on endothelial nitric oxide, stimulation of the re-

\section{KARGER}

Fax +41613061234 E-Mail karger@karger.ch www.karger.com
(C) 2011 S. Karger AG, Basel

$1420-4096 / 12 / 0353-0161 \$ 38.00 / 0$

Accessible online at:

www.karger.com/kbr
Jacek Manitius

Department of Nephrology, Hypertension and Internal Medicine

Nicolaus Copernicus University in Toruń, Collegium Medicum in Bydgoszcz

Skłodowskiej-Curie 9, PL-85-094 Bydgoszcz (Poland)

Tel. +48 52585 4030, E-Mail nerka@ nerka.cpro.pl 
nin-angiotensin system and the stimulation of thromboxane $[5,6]$. In humans the renal vascular response to infusion of angiotensin II is blunted in subjects with hyperuricemia, suggesting uric acid may be associated with an activated intrarenal angiotensin system [7].

We have used dopamine-increased creatinine clearance to assess intrarenal vascular function, as the increased glomerular filtration rate (GFR) is mediated primarily by dopamine-induced arteriolar vasodilation as opposed to an effect on tubular creatinine excretion [8]. Interestingly, a dopamine-induced increase in GFR is reduced in hyperuricemic patients with IgA nephropathy, consistent with the presence of preexisting renal vasoconstriction [8].

Erythropoietin (EPO) production is increased in the setting of low oxygen tension in renal tissue [9], and is modulated by renal blood flow [10], the status of the renal angiotensin system and other vasoconstrictive substances [11, 12]. In contrast, EPO levels fall as renal disease develops. Given this data, we hypothesized that elevated uric acid might be associated with both a blunted dopamine response and higher EPO levels in patients with Ig A nephropathy who have preserved renal function.

\section{Patients and Methods}

Forty-six untreated patients with biopsy-proven primary $\operatorname{Ig} \mathrm{A}$ nephropathy and a serum creatinine concentration of $1.07 \pm 0.30$ $\mathrm{mg} / \mathrm{dl}$ were enrolled for the study. No patients were given uric acid-lowering drugs. Patients were excluded if they had nephrotic syndrome, had secondary forms of IgA nephropathy or were on uric acid-lowering drugs. Controls consisted of 15 healthy volunteers (8 males and 7 females) with a mean age of $33.5 \pm 6.9$ years who underwent the same procedure as the patients with IgA nephropathy. The Ethical Committee of the Medical University of Bydgoszcz approved the study and informed consent was obtained from each patient.

Each subject had fasting blood sampled for uric acid, lipids and EPO, and had 24-hour urine collection for N-acetyl- $\beta$-D-glucosaminidase, uric acid, protein and creatinine. Subjects then underwent the dopamine-induced glomerular filtration response test (DIR) based on dopamine-induced changes in creatinine clearance [8]. Patients were on a normal sodium diet and were examined in the morning in the supine position after overnight fasting and 24-hour urine collections. The residual urine was discarded via a catheter introduced into the bladder and afterwards each patient ingested $20 \mathrm{ml} / \mathrm{kg}$ b.w. of water over $30 \mathrm{~min}$. Patients remained in the supine position during the whole study. The i.v. catheters were left in both antecubital veins for infusion and blood collection, respectively. Blood pressure was measured in the supine position at $30-\mathrm{min}$ intervals. After an equilibration period lasting $80 \mathrm{~min}$, the 120 -min basal collection began, followed by another 120-min collection during which dopamine was intravenously administered at a dose of $2 \mu \mathrm{g} / \mathrm{kg} / \mathrm{min}$. Whole urine col-
Table 1. Clinical parameters in subjects with IgA nephropathy and controls

\begin{tabular}{lccl}
\hline & $\begin{array}{l}\text { IgA patients } \\
(\mathrm{n}=46)\end{array}$ & $\begin{array}{l}\text { Controls } \\
(\mathrm{n}=15)\end{array}$ & $\mathrm{p}$ \\
& $33.7 \pm 8.9$ & $33.5 \pm 6.9$ & 0.9278 \\
\hline Age, years & $71.0 \pm 12.4$ & $68.5 \pm 11.4$ & 0.5052 \\
Weight, kg & $24.8 \pm 2.6$ & $23.8 \pm 2.8$ & 0.2323 \\
BMI & $2.09 \pm 1.54$ & & \\
Urine protein, g/24 h & $6.64 \pm 1.96$ & $4.76 \pm 1.25$ & 0.0009 \\
Serum uric acid, mg/dl & $0.40 \pm 0.11$ & $0.34 \pm 0.07$ & 0.0591 \\
Uric acid excretion, g/24 h & $86.7 \pm 17.4$ & $118.1 \pm 17.2$ & 0.001 \\
GFR DOP, ml/min & $4.37 \pm 1.24$ & $5.18 \pm 1.40$ & 0.0387 \\
Uric acid clearance, ml/min & & & \\
Fractional uric acid & $5.16 \pm 1.54$ & $4.44 \pm 1.26$ & 0.1097 \\
$\quad$ excretion, \% & $141.2 \pm 66.1$ & $94.3 \pm 55.2$ & 0.0013 \\
Triglycerides, mg/dl & $225.4 \pm 55.9$ & $190.8 \pm 33.8$ & 0.0278 \\
Total cholesterol, mg/dl & $142.4 \pm 46.0$ & $113.4 \pm 31.6$ & 0.0273 \\
LDL-cholesterol, mg/dl & $53.0 \pm 12.4$ & $58.5 \pm 15.5$ & 0.1670 \\
HDL-cholesterol, mg/dl & $5.38 \pm 3.32$ & $4.69 \pm 1.12$ & 0.0032 \\
NAG, U/g creatinine & $134.0 \pm 13.4$ & $112.3 \pm 5.0$ & 0.0000 \\
RR systolic, mm Hg & $85.4 \pm 8.5$ & $73.3 \pm 6.7$ & 0.0000 \\
RR diastolic, mm Hg & $48.6 \pm 8.7$ & $39.0 \pm 6.3$ & 0.0002 \\
Pulse pressure & $7.10 \pm 4.43$ & $12.83 \pm 10.09$ & 0.0630 \\
DIR, \% & $13.45 \pm 9.51$ & $10.62 \pm 4.29$ & 0.8538 \\
EPO, mU/ml & $0.616 \pm 0.277$ & $1.098 \pm 0.657$ & 0.0007 \\
DIR/EPO & & & \\
& & &
\end{tabular}

Values are means \pm SD. NAG $=\mathrm{N}$-acetyl- $\beta$-D-glucosaminidase.

lection was completed for creatinine both before and after dopamine. Blood samples for creatinine and EPO were obtained at baseline and at the beginning and end of the dopamine infusion.

DIR was calculated as follows: difference $(\Delta)$ between creatinine clearance $(\mathrm{CrCl})$ after dopamine (dop) and before dopamine (bdop), defined as DIR $=\Delta$ CrCldop - bdop/CrClbdop [\%]. Glomerular filtration rate (GFR DOP) was obtained during the DIRbasal period (without dopamine) and formed the basis for comparison between groups and fractional excretion calculations.

Analytical Methods

Serum and urinary creatinine were measured by Jaffe's method (Hitachi 912, Roche Diagnostics). To measure protein in the urine, the Exton method with sulfosalicylic acid was applied and $\mathrm{N}$-acetyl- $\beta$-D-glucosaminidase was determined colorimetrically (Roche Diagnostics). Results are expressed as units per gram of urine creatinine $\left(\mathrm{U} / \mathrm{g}_{\mathrm{cr}}\right)$. Serum, urine uric acid, triglycerides and total cholesterol were measured (Hitachi 912, Roche Diagnostics).

\section{Statistical Methods}

Data are expressed as means $\pm \mathrm{SD}$. Comparison of parameters was made using Student's test for parameters with normal distribution and a Mann-Whitney U test in case of nonparametric distribution. Correlations were made using Spearman's or Pearson's where appropriate. $\mathrm{p}<0.05$ was considered statistically significant. 


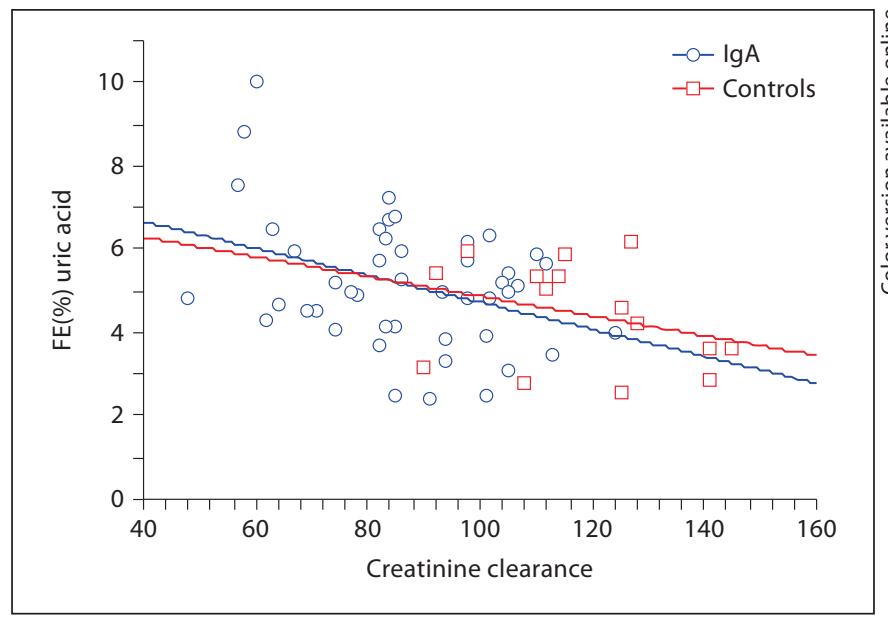

Fig. 1. Correlation of uric acid clearance with creatinine clearance. Uric acid clearance was not associated with basal creatinine clearance in controls $(\mathrm{r}=0.15, \mathrm{p}<0.58)$ or patients with IgA nephropathy $(\mathrm{r}=0.37, \mathrm{p}<0.51)$.

\section{Results}

Subjects with IgA nephropathy were hyperuricemic with lower mean uric acid clearances and baseline creatinine clearances compared to controls (table 1). In both groups, a higher uric acid was negatively associated with uric acid clearance (IgA: $\mathrm{r}=-0.75 ; \mathrm{p}<0.01$; controls: $\mathrm{r}=$ $-0.61 ; \mathrm{p}<0.01)$. Nevertheless, the fractional excretion of uric acid were similar in both groups and no significant correlations between serum uric acid and creatinine clearances were found in IgA nephropathy or in controls $(\mathrm{r}=-0.25, \mathrm{p}<0.092 ; \mathrm{r}=0.12, \mathrm{p}<0.684$, respectively).

Univariate analysis revealed differences between IgA nephropathy and controls in the relationship between GFR and uric acid clearance and fractional uric acid excretion. In IgA nephropathy, GFR correlated positively with uric acid clearance and negatively with fractional uric acid excretion $(\mathrm{r}=0.37, \mathrm{p}<0.01 ; \mathrm{r}=-0.37, \mathrm{p}<0.01$, respectively), whereas no such interactions were observed in controls $(\mathrm{r}=0.15, \mathrm{p}<0.58 ; \mathrm{r}=-0.32, \mathrm{p}<0.24$, respectively; fig. 1, 2).

Figure 3 presents the univariate relationship between uric acid clearance and its fractional excretion in IgA nephropathy and controls. Both groups showed a significant correlation; however, the relationship was more prominent in the controls than in the IgA patients (controls: $\mathrm{r}=0.87, \mathrm{p}<0.001, \mathrm{y}=1.44+0.57 \mathrm{x} ; \operatorname{IgA} \mathrm{r}=0.70$, $\mathrm{p}<0.001, \mathrm{y}=0.85+0.97 \mathrm{x})$. This means that for every

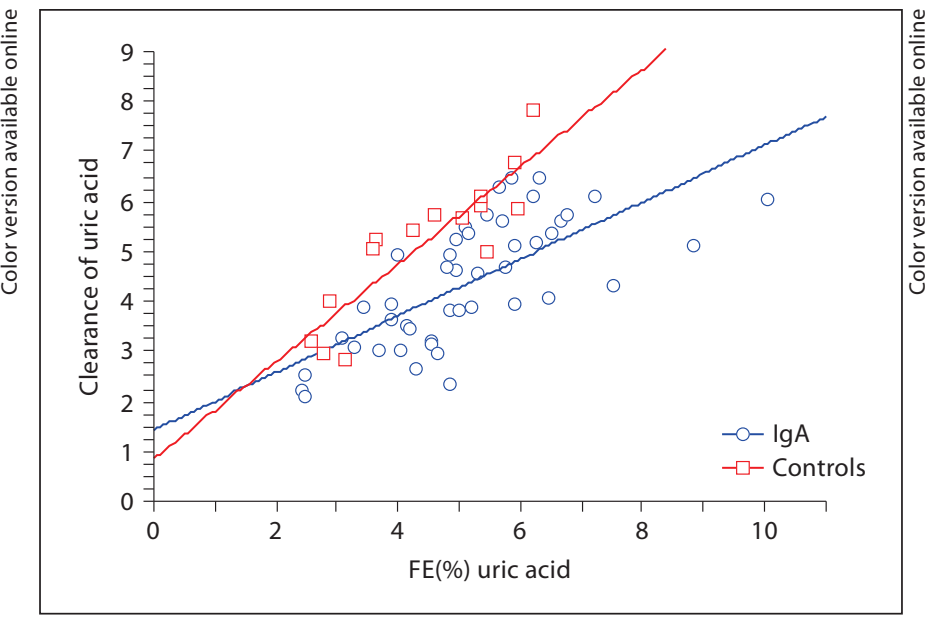

Fig. 2. Correlation of fractional excretion of uric acid with creatinine clearance. Fractional uric acid excretion did not correlate with basal creatinine clearance in controls $(r=-0.32, p<0.24)$, whereas a significant association was noted in subjects with IgA nephropathy $(\mathrm{r}=-0.37, \mathrm{p}<0.01)$.

1-unit change of fractional uric acid excretion, the change of uric acid clearance was greater in the controls than in patients with IgA nephropathy.

Correlation coefficients between uric acid clearance and basal EPO, DIR and DIR/EPO are shown in table 2. IgA nephropathy patients showed a significant correlation between uric acid clearance and EPO, DIR and DIR/ EPO, but none of them were significant in controls.

Figure 4 shows univariate correlations and slopes between basal EPO and DIR in IgA nephropathy and controls. For any given EPO concentration, the response to dopamine was more prominent in the controls than in patients with IgA nephropathy.

Correlation coefficients between blood pressure and uric acid and EPO are shown in table 3. Again, a striking difference between $\operatorname{Ig} \mathrm{A}$ and the controls was found. In IgA patients, both systolic and diastolic blood pressure correlated with serum uric acid and EPO levels, whereas this was not observed in controls.

\section{Discussion}

In this study, we examined patients with IgA nephropathy with relatively preserved renal function in order to determine the relationship of uric acid excretion with $\mathrm{EPO}$ and renal vascular function (as determined by DIR). 


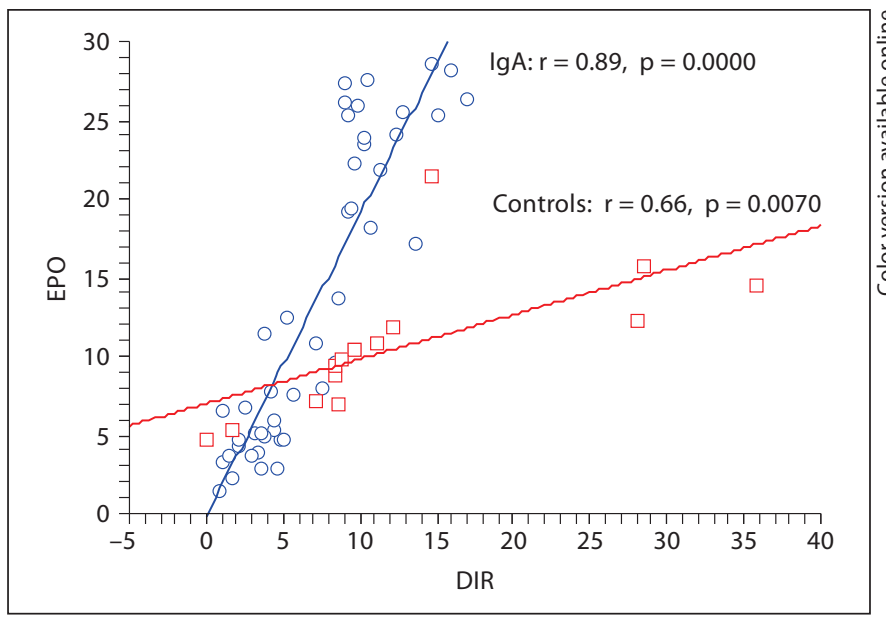

Fig. 3. Relationships between uric acid clearance and uric acid fractional excretion. Uric acid clearance was significantly associated with fractional uric acid excretion in both control subjects and patients with IgA nephropathy, and tended to be greater in the latter group.

Table 2. Univariate correlations of uric acid clearance versus EPO, DIR and DIR/EPO

\begin{tabular}{lcccccc}
\hline & \multicolumn{2}{c}{$\operatorname{IgA}(\mathrm{n}=46)$} & & \multicolumn{2}{c}{ Controls $(\mathrm{n}=15)$} \\
\cline { 2 - 3 } \cline { 6 - 7 } & $\mathrm{r}$ & $\mathrm{p}$ & & $\mathrm{r}$ & $\mathrm{p}$ \\
\hline $\mathrm{EPO}^{1}$ & 0.45 & $<0.002$ & & 0.25 & 0.361 \\
$\mathrm{DIR}^{2}$ & 0.40 & $<0.006$ & & -0.03 & 0.927 \\
$\mathrm{DIR} / \mathrm{EPO}$ & -0.30 & $<0.043$ & & -0.14 & 0.620 \\
\hline
\end{tabular}

${ }^{1}$ Serum EPO. ${ }^{2}$ Dopamine-induced response.

The first finding was that urate clearances in patients with IgA nephropathy, but not control subjects, fell with reducing GFR. In addition, the fractional excretion of uric acid increased in the patients with IgA nephropathy with lower GFR, suggesting some increased tubular secretion of urate as a compensatory mechanism to a reduction in filtration with worsening renal function $[13,14]$. GFR is known to influence urate excretion, especially in subjects whose creatinine clearances are less than $60 \mathrm{ml} /$ min [15]. Since our subjects with IgA nephropathy had a lower mean GFR than the controls, it is possible that this could explain why these correlations were observed only in the patients with IgA nephropathy.

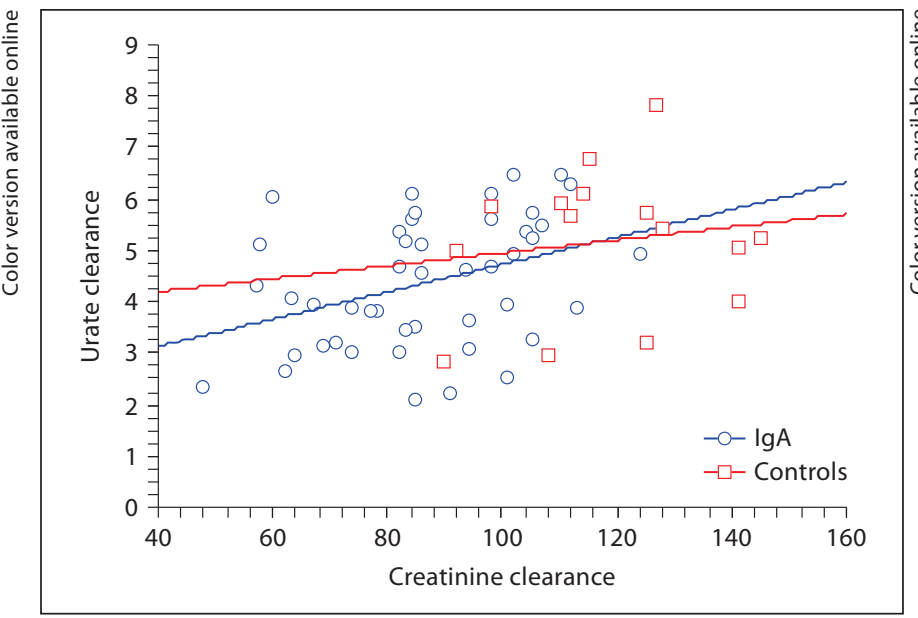

Fig. 4. Relationships of DIR with basal EPO. Univariate correlations between basal serum EPO concentration and DIR in controls and patients with IgA nephropathy.

Table 3. Univariate correlations between systolic and diastolic blood pressure, and serum uric acid and EPO

\begin{tabular}{|c|c|c|c|c|}
\hline & \multicolumn{2}{|c|}{$\operatorname{IgA}(n=46)$} & \multicolumn{2}{|c|}{ Controls $(\mathrm{n}=15)$} \\
\hline & $\mathrm{r}$ & $\mathrm{p}$ & $\mathrm{r}$ & $\mathrm{p}$ \\
\hline Systolic/UA ${ }^{1}$ & 0.53 & $<0.002$ & 0.26 & 0.341 \\
\hline Diastolic/UA & 0.57 & $<0.006$ & 0.23 & 0.420 \\
\hline Systolic/EPO ${ }^{2}$ & -0.57 & $<0.001$ & 0.06 & 0.837 \\
\hline Diastolic/EPO & -0.32 & $<0.028$ & 0.03 & 0.917 \\
\hline
\end{tabular}

${ }^{1}$ Serum uric acid. ${ }^{2}$ Basal serum EPO concentration.

The primary new finding related to the relationship of basal EPO levels with uric acid clearance between patients with IgA nephropathy and controls. While basal EPO levels were similar between groups, EPO levels positively correlated with uric acid clearance in subjects with IgA nephropathy, whereas this was not observed in control subjects. This observation would be consistent with greater renal vasoconstriction and more ischemia in subjects with IgA nephropathy, which would have the result of stimulating EPO and reducing urate clearances. One possibility is that these mechanisms might reflect effects of angiotensin II, which can stimulate EPO $[9,12,16]$ as well as reduce urate clearance [17], likely by causing renal vasoconstriction with a fall in oxygen availability for tu-

Sulikowska/Johnson/ Odrowąż-Sypniewska/Manitius 
bular transport $[18,19]$. Intrarenal angiotensin II may also be higher in IgA nephropathy subjects due to proteinuria, hypertension or elevations in serum uric acid [6, 20-22], and can be reflected by increased urinary angiotensinogen levels $[23,24]$. The observation that DIR tended to be lower in subjects with IgA nephropathy compared to controls is consistent with this hypothesis ( $\mathrm{p}<$ 0.06 ; table 1 ). We also found a more pronounced slope between basal EPO and DIR (fig. 4) as well as a lower DIR/EPO ratio (dopamine-induced response/basalEPO), which is consistent with the presence of greater renal vasoconstriction in IgA nephropathy patients (table 1). In these patients the response to dopamine was $44 \%$ lower compared to controls, consistent with the presence of greater vasoconstriction. These studies are consistent with our previous data which showed that the functional status of postglomerular vessels is worse in IgA nephropathy patients than in healthy volunteers [8].

The possibility that early IgA nephropathy could be associated with significant renal vasoconstriction associated with the elevation in serum uric acid might also explain the alterations in EPO levels. Hence, while GFR is still relatively preserved, higher uric acid production in IgA nephropathy patients might be associated with lower urate clearances which might correlate with increasing renal vasoconstriction and increasing basal EPO levels. In contrast, once GFR falls significantly, urate clearances will fall with an increase in serum uric acid and an increase in fractional urate excretion despite continued renal vasoconstriction and tubular injury. While the increase in fractional urate excretion could reflect a compensatory response, there is still the possibility that it is secondary to tubular injury that may interfere with the ability of the proximal tubule to reabsorb uric acid effectively (as noted by the increasing $\mathrm{N}$-acetyl- $\beta$-D-glucosaminidase levels). The tubular injury might also reduce EPO levels and impair the EPO response.

IgA nephropathy patients also had higher blood pressure than controls (table 1) and hypertension was strongly associated with hyperuricemia, even in subjects with normal GFR. These data are consistent with increasing evidence for both an association as well as potential causal role between serum uric acid and hypertension [25]. Interestingly, the mechanism by which uric acid is proposed to cause hypertension is in part by inducing renal vasoconstriction [25].

In conclusion, there is a relationship between serum uric acid, renal vasoconstriction and EPO in subjects with IgA nephropathy even before GFR falls. While the cause and effect cannot be deduced due to the cross-sectional nature of the study, the data is consistent with decreased urate clearances, reflecting relatively greater renal vasoconstriction with preferential efferent arteriolar constriction and preservation of GFR. During this period, EPO levels correlate inversely with urate clearances. As renal injury progresses, serum uric acid rises with an increase in fractional urate excretion, which may act as a compensatory response. Time course and or intervention studies will be necessary to evaluate this potential explanation.

\section{Acknowledgment}

This work was supported in part by grant PDS 209 from the Nicolaus Copernicus University in Toruń, Poland.

\section{References}

1 Myllymaki J, Honkanen T, Syrjanenen J, Helin H, Rantala I, Pasternak A, Mustonen J: Uric acid correlates with severity of histopathological parameters in IgA nephropathy. Nephrol Dial Transplant 2005;20:89-85.

2 Ohno I, Hosoya T, Gomi H, Ichida K, Okabe $\mathrm{H}$, Hikita M: Serum uric acid and renal prognosis in patients with IgA nephropathy. Nephron 2001;87:333-339.

- 3 Sanchez-Lozada LG, Tapia E, Santamaria J, Avila-Casado C, Soto V, Nepomuceno T, Rodriguez-Iturbe B, Johnson RJ, Herrera-Acosta J: Mild hyperuricemia induces vasoconstriction and maintains glomerular hypertension in normal and remnant kidney rat. Kidney Int 2005;67:237-247.

Vasoconstriction, EPO and Urate Excretion in IgA
-4 Messerli FH, Frohlich ED, Dreslinski GR, Suarez DH, Aristimuno GG: Serum uric acid in essential hypertension: an inidicator of renal vascular involvement. Ann Intern Med 1980;93:817-821.

5 Khosla UM, Zharikov S, Finch JL, Nakagawa T, Roncal C, Mu W, Krotova K, Block ER, Prabhakar S, Johson RJ: Hyperuricemia induces endothelial dysfunction. Kidney Int 2005;67:1739-1742.

6 Mazzali M, Kanelis J, Han L, Feng L, Xia YY, Chen Q, Kang DH, Gordon LK, Watanabe S, Nakagawa T, Lan HY, Johnson RJ: Hyperuricemia induces a primary arteriolopathy in rats by a blood pressure-independent mechanism. Am J Physiol Renal Physiol 2002; 282:F991-F997.
7 Perlstein TS, Gumeniak O, Hopkins PN, Murphey LJ, Brown NJ, Williams GH, Hollenberg NK, Fisher ND: Uric acid and the state of the intrarenal renin-angiotensin system in humans. Kidney Int 2004;66: $1465-1470$

8 Sulikowska B, Manitius J, OdrowążSypniewska G, Łysiak-Szydłowska W, Rutkowski B: Uric acid excretion and dopamine induced glomerular filtration response in patients with IgA glomerulonephritis. Am J Nephrol 2008;28:391-396.

-9 Ratclife PJ: Molecular biology of erythropoietin. Kidney Int 1993;44:887-904. 
10 Langenfeld MRW, Veelken R, Scobel HP, Friedrich A, Schmieder RE: Is endogenous erythropoietin a pathogenetic factor in the development of essential hypertension? Nephrol Dial Transplant 1997;12:1155-1160.

-11 Hand MF, Haynes WG, Johnstone HA, Anderton JL, Webb DJ: Erythropoietin enhances vascular responsiveness to norepinephrine in renal failure. Kidney Int 1995;48: 806-813.

12 Nowicki M, Kokot F, Więcek A: Influence of the renin-angiotensin system stimulation on erythropoietin production in patients with various forms of arterial hypertension. Nephron 1993;65:527-532.

13 Garcia-Puig J, Mateos-Anton F, Munos-Sanz A, Gaspar G, Lesmes A, Ramos T, Ortiz-Vazguez J: Renal handling of uric acid in normal subjects by means of the pyrazinamide and probenecid tests. Nephron 1983;35:183-186.

14 Steele TH, Rieselbach RE: The contribution of residual nephrons within chronically diseased kidney to urate homeostasis in man. Am J Med 1967;43:876-886.

15 Maly J, Schuck O: Renal uric acid excretion in patients with chronic pyelonephritis. Int Urol Nephrol 1973;5:209-216.
16 Vlahakos DV, Balodimos C, Papachristopoulos V, Vassilakos P, Hinari E, Vlachojannis JG: Renin-angiotensin system stimulates erythropoietin secretion in chronic hemodialysis patients. Clin Nephrol 1995;43:53-59.

17 Ferris TF, Gorden P: Effect of angiotensin and norepinephrine upon urate clearance in man. Am J Med 1968;44:359-365.

18 Welch WJ, Blau J, Xie H, Chabrashvili T, Wilcox CS: Angiotensin-induced defects in renal oxygenation: role of oxidative stress. Am J Physiol Heart Circ Physiol 2005; 288: $\mathrm{H} 22-\mathrm{H} 28$

19 O'Connor PM, Kett MM, Anderson WP, Evans RG: Renal medullary tissue oxygenation is dependent on both cortical and medullary blood flow. Am J Physiol Renal Physiol 2006; 290:F688-F694.

20 Rodriguez-Iturbe B, Herrera-Acosta J, Johnson RJ: Interstitial inflammation, sodium retention and the pathogenesis of nephritic edema: a unifying hypothesis. Kidney Int 2002;62:1379-1384.

21 Alvarez Z, Quiroz Y, Nava M, Pons H, Rodriguez-Iturbe B: Overload proteinuria is followed by salt-sensitive hypertension caused by renal infiltration of immune cells. Am J Physiol Renal Physiol 2002;283:F1136F1141.
22 Watanabe S, Kang DH, Feng L, Nakagawa T, Kanellis J, Lan H, Mazzali M, Johnson RJ: Uric acid, hominoid evolution and the pathogenesis of salt sensitivity. Hypertension 2002;30:355-360.

23 Nishiyama A, Konishi Y, Ohashi N, Morikawa T, Urushihara M, Maeda I, Hamada M, Kishida M, Hitomi H, Shirahashi N, Kobori $\mathrm{H}$, Imanishi M: Urinary angiotensinogen reflects the activity of intrarenal rennin-angiotensin system in patients with IgA nephropathy. Nephrol Dial Transplant 2011;26: 170-177.

24 Ohashi N, Katsurada A, Miyata K, Satou R, Saito T, Urushihara M, Kobori H: Activation of reactive oxygen species and the renin-angiotensin system in IgA nephropathy model mice. Clin Exp Pharmacol Physiol 2009;36: 509-515.

25 Johnson RJ, Feig DI, Nakagawa T, SanchezLozada LG, Rodriquez-Iturbe B: Pathogenesis of essential hypertension: historical paradigms and modern insights. J Hypertens 2008;26:381-391. 